\begin{tabular}{|l|l|}
\hline Postprint Version & 1.0 \\
\hline Journal website & $\underline{\text { http://www.sciencedirect.com/science/journal/01650327 }}$ \\
\hline $\begin{array}{l}\text { Pubmed link } \\
\text { http://www.ncbi.nlm.nih.gov/entrez/query.fcgi?db=pubmed\&cmd=Retrieve\&dop }\end{array}$ \\
\hline DOI & $\underline{\mathrm{t}=\text { AbstractPlus\&list_uids=16956665\&query_hl=8\&itool=pubmed_docsum }}$ \\
\hline
\end{tabular}

This is a NIVEL certified Post Print, more info at http://www.nivel.eu

\title{
Indications for antidepressant drug prescribing in general practice in the Netherlands
}

\section{Research report}

\author{
H. GARDARSDOTTIR ${ }^{A}$, E.R. HEERDINK ${ }^{\text {A }}$, L. VAN DIJK ${ }^{\text {B }}$, A.C.G. EGBERTS ${ }^{\text {A }}$ \\ aDepartment of Pharmacoepidemiology and Pharmacotherapy, Utrecht Institute for Pharmaceutical \\ Sciences (UIPS), Utrecht University, P.O. Box 80082, 3508 TB Utrecht, The Netherlands \\ ${ }^{b}$ Netherlands Institute for Health Services Research (NIVEL), Utrecht, The Netherlands \\ *Corresponding author. Tel.: +31 30253 7324; fax: +31 30253 9166. E-mail address: \\ E.R.Heerdink@pharm.uu.nl (E.R. Heerdink).
}

\begin{abstract}
Background: The intensity of the use of antidepressants in large populations can nowadays relatively easily be estimated using databases encompassing prescription data. There are shortcomings when using prescription databases as they contain no clinical data on patient illness. Antidepressants are prescribed for different illnesses, thus information on the indications could help when interpreting results from database studies on antidepressant drug use. The aim of this study is to investigate for which indications antidepressants are being prescribed in general practice in the Netherlands.
\end{abstract}

Methods: Data were obtained from the Second Dutch National Survey of General Practice, carried out by NIVEL $(N=385,461)$. Patients, 18 years and older, who received an antidepressant prescription from a general practitioner in 2001 were selected $(N=13,835)$. Indications for antidepressant drug prescribing were identified using time windows of different lengths.

Results: Antidepressants are most often being prescribed for depression (45.5\%) and anxiety/panic disorders (17.2\%). For these indications lengthening the time window around prescription date from 0 to 180 days resulted in an increase of $20-40 \%$ in antidepressant drug users identified with these indications.

Limitation: None of our selected indications could be identified in the physician-patient contact file for about a third of the antidepressant drug users. The study was performed in a general practice setting and did not include antidepressant users who consult psychiatrists.

Conclusion: GPs prescribe antidepressants predominantly for treating depression. However, using antidepressant drug as a proxy for identifying depressed patients in a prescription database should be done with caution and when possible in combination with clinical data. 


\section{INTRODUCTION}

Antidepressant drug use has increased dramatically over the past decade (Rosholm et al., 1997; Lawrenson et al., 2000). Possible explanations for this increase are thought to be many, including the introduction of new antidepressants, increased depression awareness, acceptability of pharmacological treatment, better diagnosis, broadened indications and longer treatment periods (Barbui et al., 1999; Stafford et al., 2001; Pirraglia et al., 2003; Hemels et al., 2002; Meijer et al., 2004). The intensity and dynamics of the use of antidepressants in large populations can nowadays quite easily be estimated using databases encompassing prescription data (Tamblyn et al., 1995; Melfi and Croghan, 1999; Henriksson et al., 2003). There are, however, shortcomings when using these databases as they often only contain prescription data and no clinical data including information on the type of illness the treatment is intended for.

In the Netherlands antidepressants are approved not only for use in patients who suffer from depression but also for patients with nocturnal enuresis, social phobia, generalized anxiety disorders, obsessive-compulsive disorders, panic disorders and eating disorders (Anon, 2000). In addition, the antidepressants are used for some clinically accepted off-label indications such as sleeping disorders (Walsh, 2004), urinary incontinence (Zinner et al., 2004), headache (Colombo et al., 2004) and neuropathic pain (Maizels and McCarberg, 2005). Previous studies have shown that use of antidepressants have even gone beyond the approved and clinically accepted off-label indications (Volkers et al., 2005). Given the different diseases and symptoms that the antidepressants can be prescribed for and the vast amount of research that has been done on antidepressant drug use (Bingefors et al., 1996; Joffe et al., 2001; Hemels et al., 2002; Barbui et al., 2003; Hansen et al., 2003; Rahimtoola et al., 2003; Helgason et al., 2004; Meijer et al., 2004) it is of interest to investigate the indications for antidepressant drug prescription. Information on how the antidepressants are being prescribed for the different symptoms and illnesses could help us in better understanding and interpreting results from prescription database studies done on antidepressant drug use e.g. where antidepressant drug use is set as a proxy for treatment of depression.

When identifying indication for antidepressant drug prescribing using general practice databases it is important that the indication is registered in the physician-patient contact file when a prescription is given. Not registering the indication for prescribing might occur in different situations e.g. for new users where antidepressant drug therapy can be initiated before the general practitioner has come to a diagnosis. To try to overcome these problems time windows of different length around prescription date can be applied. By applying this method more physician-patient contact moments are used to identify the indication for prescribing.

The aim of this study is to investigate for which indications antidepressants are being prescribed in general practice in the Netherlands. In addition, we will investigate how using different time windows around prescription date will influence identifying indications for antidepressant drug prescribing in a general practice database.

\section{METHODS}

\subsection{Setting and study population}

Data of this study were obtained from the Second Dutch National Survey of General Practice (DNSGP-2) which was carried out in 2001 by the Netherlands Institute for Health Services Research (NIVEL) and has been described in detail elsewhere (Westert et al., 2005). In short, 195 general practitioners (GPs) in 104 practices registered details of all physician-patient contacts during 12 months in a standardized way. GPs were trained during an intensive course on coding practices and problems by the LINH (Dutch Information Network GPs). The GPs registered all health problems presented within a consultation and diagnoses were coded using the International Classification of Primary Care, ICPC (Lamberts and Wood, 1987).

In addition, all prescriptions made by the GPs were registered. The DNSGP-2 includes prescription data containing information on the dispensed drug, dispensing date, amount dispensed and prescribed dosage regimen. Drugs are coded according to the Anatomical Therapeutic Chemical (ATC) classification (Anon, 2002). Each patient is identified with an anonymous unique patient-identification code. 
The DNSPG-2 population consisted of patients from 104 general practices in the Netherlands $(N=385,461)$. Eight practices were excluded from the DNSGP-2 population for the present study due to insufficient contact and/or data collection. The source population included all individuals registered in the 96 general practices in the Netherlands in the year $2001(N=289,692)$. The study population consisted of patients, 18 years and older, from the 96 practices which received at least one antidepressant prescription from their GP in the year $2001(N=13,835)$. The 1-year prevalence of antidepressant drug use in the study population was $6.0 \%$ which is similar to the 1 -year prevalence of antidepressant drug use in 2001 in the Netherlands (Anon, 2006a,b).

In the Netherlands the following antidepressants were available and prescribed during the study period: tricyclic antidepressants (TCAs: amitriptyline, clomipramine, desipramine, dosulepin, doxepin, imipramine, maprotiline, nortriptyline, trimipramine), selective serotonin reuptake inhibitors (SSRIs: citalopram, fluoxetine, fluvoxamine, paroxetine, sertraline) and other (mianserin, mirtazapine, moclobemide, nefazodone, trazodone, tranylcypromine, venlafaxine).

\subsection{Indications}

The indications investigated in this study were based on officially approved indications for the antidepressants in the Netherlands (Anon, 2000). In addition, some in clinical practice accepted offlabel indications were selected such as sleeping disorders, migraine/headache prophylaxis and neuropathic pain. The indications for antidepressant prescription that investigated in this study were depression/feeling depressed (ICPC codes: P03, P76), anxiety/panic disorder/feeling anxious (ICPC code: P01, P74), obsessive-compulsive disorder/phobia (ICPC code: P79), sleeping disorders (ICPC code: P06), migraine/cluster headache (ICPC code: N89, N90), neuropathic pain (ICPC code: N03, N92, N94), eating disorders (ICPC code: T06) and enuresis/incontinence (ICPC code: P12, U04).

\subsection{Data analysis}

The prescription date was defined as the date of first antidepressant prescription that the patient received from the GP in year 2001. An indication was considered as the GP's reason for prescribing an antidepressant when one of the ICPC codes could be identified in the physician-patient contact file. The registries in the physician-patient contact files were available from October 2000 until June 2002. It was possible for the antidepressant drug users to have more than one indication registered in the physician-patient contact file. The indications were identified by searching the physician-patient contact file using prescription date together with different time windows of 0, 28, 60, 120 and 180 days. Each time window extends for equal amount of days prior to and post prescription date e.g. a time window of 28 days represents the time range of 14 days prior to 14 days post prescription date. The average duration of use for the first antidepressant prescription in our study population was 40 days. A time window of 180 days, 90 days prior to and 90 days post prescription date, was considered sufficiently wide to include at least two GP visits and was for that reason used as a reference to evaluate what effect the length of time window has on identifying indications for antidepressant drug prescribing in the physician-patient contact file. The 180-day time window reference measurement was compared to the measurements where $0,28,60$ and 120 days time windows were used to identify indication for antidepressant prescribing. The characteristics of patients identified with different indications compared and odds ratios (OR) with 95\% confidence intervals (CI) were calculated. A further analysis was done on the antidepressant drug users who had one of the selected indications, excluding those that did not have any of the selected indications registered in their physician-patient contact file. The cumulative change in amount of antidepressant users where an indication was identified in the physician-patient contact file was investigated over time. The time span investigated started at 90 days prior to prescription date and ended at 90 days post prescription date.

\section{RESULTS}

General characteristics of the study population are presented in Table 1 along with the four most frequently prescribed antidepressants. The study population was mainly female (68.7\%) with a mean age of 50.8 years. The four most frequently prescribed antidepressants within our study population were the same as the four most frequently used antidepressants in the general Dutch population (Anon, 2005). 


\section{[ TABLE 1 ]}

Indications for antidepressant prescribing in 2001 in general practice identified when using a 180-day time window around prescription date are presented in Table 2 . In the study population $(N=13,835)$, depression (45.4\%) and anxiety/panic disorders (17.2\%) represent the most common indications for antidepressant drug prescribing. About one third of the antidepressant drug users did not have any of the selected indications registered in the physician-patient contact file. When looking at the indications for antidepressant drug prescribing within each group of antidepressant drugs it was observed that more than half of the TCA users did not have the indications we investigated in their respective physician- patient contact file in comparison to 30\% of the SSRI users. In addition, the proportion of patients that did not have one of our selected indications registered in their physicianpatient contact files was different for the antidepressant drug users who were receiving the specific antidepressant for the first time and those who had received the specific antidepressant before. About $40 \%$ of the antidepressant drug users who received the specific antidepressant for the first time had none of our selected indications in their physician-patient contact file, while for the antidepressant drug users that had registered prior use of the specific antidepressant this proportion was $28 \%$.

\section{[ TABLE 2 ]}

We found that women were more likely than men to have the indications incontinence/enuresis (OR=3.3, 95\% CI: 2.0, 5.3) and headache/migraine (OR=2.8, 95\% CI: 1.9, 4.1) in their physicianpatient contact file while men were more likely to have the indication neuropathic pain (OR=1.5, 95\% CI: 1.1, 2.0). The 18- to 30-year-old antidepressant drug users were more likely than the $>60$ year old to have the indications depression ( $\mathrm{OR}=1.5,95 \% \mathrm{CI}: 1.3,1.6)$, anxiety/panic disorders $(\mathrm{OR}=1.4,95 \%$ CI: 1.2, 1.6) or obsessive-compulsive disorders/phobia (OR=5.3, 95\% CI: 3.1, 8.9) registered in their physician-patient contact file while the $>60$-year-old antidepressant drug users where more likely to have the indications neuropathic pain (OR=3.7, 95\% CI: 1.7, 8.2) or none of our selected indications registered (OR=1.7, 95\% CI: 1.5, 2.0). The antidepressant drug users who received a second antidepressant prescription within the 90 days following prescription date were more likely to have the indications depression (OR=1.6, 95\% CI: 1.4, 1.7) and anxiety/panic disorder (OR=1.2, 95\% CI: 1.1, 1.4) registered in the physician-patient contact file when compared to those who did not receive a second antidepressant within the 90 days following prescription date. Antidepressant drug users who did not receive a second antidepressant prescription within 90 days from prescription date were more likely to have the indication neuropathic pain $(\mathrm{OR}=1.6,95 \% \mathrm{CI}$ : 1.1, 2.1) or none of our selected indications (OR=1.4, 95\% CI: 1.3, 1.5) registered in the physician-patient contact file.

The indications for antidepressant drug prescribing in general practice identified using time windows of different lengths around the prescription date are presented in Table 3. For the main indications (depression, anxiety/panic disorder, obsessive-compulsive disorder/ phobia) lengthening the time window from 0 days to 180 days resulted in an increase of about $20-40 \%$ in antidepressant drug users identified with the indications. For the indications eating disorders and neuropathic pain the increase was about $50 \%$ and for the indications sleeping disorder, headache/migraine and enuresis/ incontinence the increase was almost 70-80\% when lengthening the time window from 0 days to 180 days. The total amount of antidepressant drug users with one of our selected indications registered and the amount where none of our selected indication was found in the physician-patient contact file are presented graphically for the different time windows in Fig. 1 . The figure displays that increasing the time window from 0 days to 180 days results in a 30\% increase in the amount of antidepressant drug users for which an indication is identified. When investigating only the antidepressant drug users that had one of our selected indications in their physician-patient contact file $(N=8879)$ it appears that the indications are most often registered on prescription date. Fig. 2 displays the cumulative changes in amount of antidepressant drug users identified, where any of our selected indications are registered in their physician-patient contact file, over a time window from 90 days prior to until 90 days post prescription date. 


\section{[ TABLE 3 ]}

\section{[ FIGURE 1-2 ]}

\section{DISCUSSION}

Our study shows that depression is the most common indication for antidepressant drug prescribing in general practice. About $45 \%$ of the antidepressant drug users had the antidepressant indicated for treating depression which is a bit lower in proportion than what has been reported in earlier studies done in the Netherlands in 1994/95 (de Waal et al., 1996) and in 1996 (Egberts et al., 1998). In addition, our study shows that the proportion of antidepressant drug users with the indication depression registered in the physician-patient contact file is related to characteristics such as type of antidepressant, gender, age, time-window and whether or not a second antidepressant prescription is prescribed in the 90 days following first prescription. The indications anxiety and sleeping disorders were quite frequently found registered in the physician-patient contact file of the antidepressant drug users as these disorders are known to be co-morbid with depression (Ballenger et al., 1999; Roberts et al., 2000).

Depression and anxiety are indications for prescribing that are most often registered on prescription date (0 days time window) while the indications neuropathic pain, headache/migraine, sleeping disorders and enuresis/ incontinence are less frequently registered on prescription date. With regard to depression expanding the time window did not result in a large increase in total amount of antidepressant drug users identified with depression. For other indications such as enuresis/ incontinence, sleeping disorders and headache/migraine expanding the time window from 0 days to 180 days around prescription date had a large effect on the number of antidepressant drug users identified with the previously mentioned indications. Although most of the antidepressant drug users with the selected indications registered in their physician-patient contact file had the indication registered on prescription date about $14 \%$ got the indication registered post prescription date, suggesting that in some cases the GPs base the indication for prescribing on the effect of the therapy. This implies that when use of a specific medicine in combination with a diagnostic code(s) is used to identify patients with a specific disease the length of time windows applied can influence the outcome. Many of the antidepressant drug users did not have any of our selected indications for prescribing registered in the physician-patient contact file. A possible explanation could be that the GPs did not register the indication for prescribing in the physician-patient contact register. This could happen when patients visit the GP due to a disease, unrelated to their antidepressant drug use, and get a re-fill on their antidepressant drug prescription. When investigating the age of the antidepressant drug users who did not have any of our selected indications registered in the physician-patient contact file we found that these were mostly older users. Older patients are more likely to be in poor health, suffering from other co-morbid conditions, using more medication and having more frequent consultations with the GP, which would support previously mentioned explanation. Another reason could be that some of the patients pick up a prescription at the general practice without a consultation with the GP, resulting in a prescription without a registered indication for prescribing. This kind of situation would more likely apply to the younger patients who just 'drop by' to pick up a prescription. In addition, there is always the possibility that a diagnosis is not registered due to diagnostic uncertainty, where the GP is still in the phase of evaluating the patient. When we investigated the antidepressant drug users who were receiving their antidepressant for the first time we found that about $40 \%$ of them had none of our selected indications registered in the physician-patient contact file. For the antidepressant drug users who had received their antidepressant drug before 2001 this proportion was about 28\%. This supports our theory that the GP might not register the indication for antidepressant drug prescribing as he/she is still evaluating the patient. Finally, there is also the possibility that the GP prescribed the antidepressant for an indication other than those we selected to investigate in this study.

Limitations to our study are firstly the large amount of antidepressant drug users for whom none of our selected indications could be identified in the physician-patient contact file. We do not know the reasons for the indications not being registered in the physician-patient contact file and if this information were available it could influence the outcome of our study. Most of the antidepressant drug users had physician-patient file data information available from October 2000 until June 2002. 
An extra analysis was performed to specifically investigate if our results where being influenced by patients who received their antidepressants in the first three months of 2001 and did not have a full 90day history prior to prescription date. The analysis verified that this limitation did not influence our results. Secondly, the study was performed in a general practice setting and did not include the antidepressant users who receive their antidepressants from a psychiatrist or those submitted to psychiatric wards. These patients would represent a more severely diseased group, which could influence how the antidepressant users are divided over the different indications for antidepressant drug prescribing.

As we have shown it is difficult to draw a conclusion about depression in the general population based on prescription data only. Prescription data can be used in combination with clinical data to identify specific diseases (Claxton et al., 2000; Pladevall et al., 2004). This is a useful method when constructing patient cohorts of e.g. type I diabetic patients, as insulin is only indicated for treatment of diabetes. However, when considering medicines that are indicated for treatment of more than one disease, like the antidepressants, it gets more complicated to construct these types of cohorts. From our study we see that although depression is the main indication for antidepressant drug prescribing it is not the only one. Using antidepressant drug use as a proxy for identifying depressed patients in a prescription database should therefore be done with caution and when constructing cohorts of depressed antidepressant drug users, prescription data should preferably be used in combination with clinical data. Not being able to identify why the antidepressant treatment is being initiated makes it difficult to study depression in databases without accepting some bias into the study. It would be more proper for these types of research to use antidepressants as a name instead.

In conclusion, GPs prescribe antidepressants predominantly for treating depression and most of the time they register the indication for prescribing on prescription date. When use of a specific medicine in combination with a diagnostic code(s) is used to identify patients with a specific disease the length of time windows around prescription date applied can influence the outcome. A proportion of the antidepressant drug users receives the possible indication for prescribing prior to or post antidepressant drug prescription. Further research is recommended to investigate if and how these antidepressant drug users differ from those that receive indication for prescribing on prescription date.

\section{TABLES AND FIGURES}

Table 1

Patient characteristics of the study population, including information about the four most frequently prescribed antidepressants within the study population $(N=13,835)$

\begin{tabular}{lrr}
\hline & $N$ & $\%$ \\
\hline Gender & & \\
Male & 4328 & 31.3 \\
Female & 9507 & 68.7 \\
Age (years) & & \\
18-30 & 1618 & 11.7 \\
$31-45$ & 4228 & 30.6 \\
$46-60$ & 4168 & 30.1 \\
$>60$ & 3821 & 27.6 \\
Prescribed antidepressant & & \\
TCA & 3639 & 26.3 \\
SSRI & 8366 & 60.5 \\
Other & \\
4 most frequently prescribed antidepressants & 1830 & 13.2 \\
Paroxetine & & \\
Amitriptyline & 5318 & 38.4 \\
Fluoxetine & 2391 & 17.3 \\
Mirtazapine & 1144 & 8.3 \\
\hline
\end{tabular}

\footnotetext{
a Other antidepressants: mianserin, mirtazapine, moclobemide,
} nefazodone, trazodone, tranylcypromine, venlafaxine. 
Gardarsdottir, H., Heerdink, E.R., Dijk, L. van, Egberts, A.C.G.

Indications for antidepressant drug prescribing in general practice in the Netherlands. Journal of Affective Disorders, 98, 2007, nr. 1-2, p.109-115

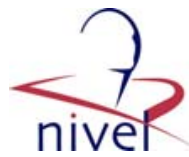

Table 2

Indications for antidepressant prescribing in 2001 in general practice identified by using a 180-day time-window around the prescription date $\left(N_{\text {total }}=13,835\right)$

\begin{tabular}{|c|c|c|c|c|c|c|c|c|}
\hline \multirow[t]{2}{*}{ Indication } & \multicolumn{2}{|c|}{ Total users $^{\mathrm{a}}$} & \multicolumn{2}{|l|}{ TCA } & \multicolumn{2}{|l|}{ SSRI } & \multicolumn{2}{|c|}{ Other } \\
\hline & $N$ & $\%$ & $N$ & $\%$ & $N$ & $\%$ & $N$ & $\%$ \\
\hline Depression/feeling depressed & 6296 & 45.5 & 899 & 24.7 & 4472 & 53.5 & 925 & 50.5 \\
\hline Anxiety/panic disorder/feeling anxious & 2380 & 17.2 & 521 & 14.3 & 1561 & 18.7 & 298 & 16.3 \\
\hline Obsessive-compulsive disorder/phobia & 200 & 1.4 & 32 & 0.9 & 145 & 1.7 & 23 & 1.3 \\
\hline Eating disorders & 35 & 0.3 & 1 & 0.03 & 31 & 0.4 & 3 & 0.2 \\
\hline Enuresis/incontinence & 170 & 1.2 & 55 & 1.5 & 96 & 1.1 & 19 & 1.0 \\
\hline Sleeping disorders & 1292 & 9.3 & 427 & 11.7 & 662 & 7.9 & 203 & 11.1 \\
\hline Headache/migraine & 231 & 1.7 & 78 & 2.1 & 124 & 1.5 & 29 & 1.6 \\
\hline Neuropathic pain & 161 & 1.2 & 126 & 3.5 & 30 & 0.4 & 5 & 0.3 \\
\hline None of above & 4956 & 35.8 & 1870 & 51.4 & 2461 & 29.4 & 625 & 34.2 \\
\hline
\end{tabular}

a Total users exceed the total number of antidepressant drug users as the patients can have more than one indication registered in the physicianpatient contact file.

Table 3

Indications for antidepressant drug prescribing in general practice in the Netherlands identified using different time windows ${ }^{\mathrm{a}}$ around prescription date $\left(N_{\text {total }}=13,835\right)$

\begin{tabular}{|c|c|c|c|c|c|c|c|c|c|c|}
\hline \multirow[t]{2}{*}{ Indication } & \multicolumn{2}{|c|}{0 days } & \multicolumn{2}{|c|}{28 days } & \multicolumn{2}{|c|}{60 days } & \multicolumn{2}{|c|}{120 days } & \multicolumn{2}{|c|}{180 days } \\
\hline & $N$ & $\%$ & $N$ & $\%$ & $N$ & $\%$ & $N$ & $\%$ & $N$ & $\%$ \\
\hline Depression/feeling depressed & 4861 & 35.1 & 5239 & 37.9 & 5541 & 40.1 & 5975 & 43.2 & 6296 & 45.5 \\
\hline Anxiety/panic disorder/feeling anxious & 1398 & 10.1 & 1672 & 12.1 & 1909 & 13.8 & 2177 & 15.7 & 2380 & 17.2 \\
\hline Obsessive-compulsive disorder/phobia & 133 & 1.0 & 154 & 1.1 & 171 & 1.2 & 191 & 1.4 & 200 & 1.4 \\
\hline Eating disorder & 19 & 0.1 & 21 & 0.2 & 25 & 0.2 & 32 & 0.2 & 35 & 0.3 \\
\hline Enuresis/incontinence & 33 & 0.2 & 65 & 0.5 & 89 & 0.6 & 134 & 1.0 & 170 & 1.2 \\
\hline Sleeping disorders & 419 & 3.0 & 657 & 4.7 & 852 & 6.2 & 1102 & 8.0 & 1292 & 9.3 \\
\hline Headache/migraine & 58 & 0.4 & 81 & 0.6 & 127 & 0.9 & 190 & 1.4 & 231 & 1.7 \\
\hline Neuropathic pain & 79 & 0.6 & 103 & 0.7 & 117 & 0.8 & 139 & 1.0 & 161 & 1.2 \\
\hline None of above & 7079 & 51.3 & 6480 & 46.8 & 6009 & 43.4 & 5406 & 39.1 & 4956 & 35.8 \\
\hline
\end{tabular}

Each time window extends for equal amount of days prior to and post prescription date e.g. a time window of 28 days represents the time range from 14 days prior to 14 days post prescription date.

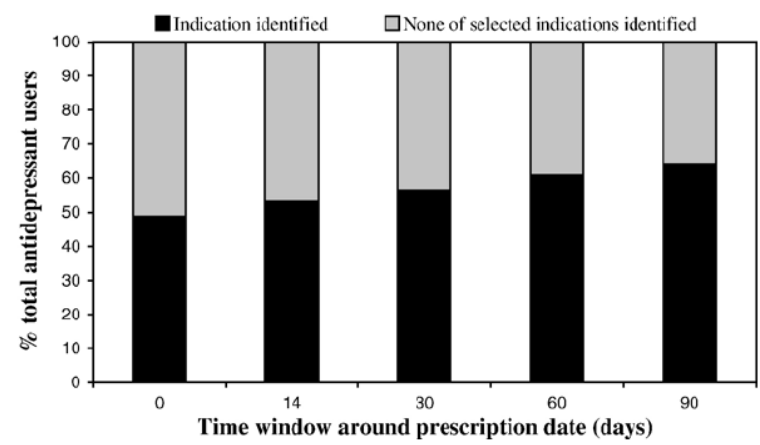

Fig. 1. Proportion of total antidepressant drug users where the selected indications are identified and where none of selected indications are identified when using different time windows around prescription date.

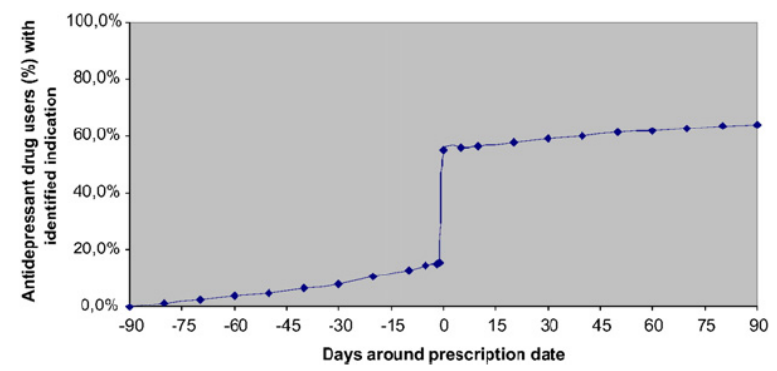

Fig. 2. Cumulative changes in amount of antidepressant drug users identified with one of the selected indications in their physicianpatient contact files over time. The time window ranges from 90 days prior to until 90 days post prescription date (0). 


\section{REFERENCES}

1. Anon, 2000. Farmacotherapeutisch Kompas 2000/2001, de Commissie Farmaceutische Hulp van het College voor zorgverzekeringen (CVZ), Amstelveen.

2. Anon, 2002. Anatomical Therapeutic Chemical (ATC) Classification Index. WHO Collaborating Centre for Drug Statistics Methodology, Oslo.

3. Anon, 2005. GIP databank, The Netherlands [online]. Available from http://www.gipdatabank.nl/index.asp [Accessed 6 September 2005].

4. Anon, 2006a. Central Bureau of Statistics, The Netherlands. [online]. Available from www.cbs.nl [Accessed 31 May 2006].

5. Anon, 2006b. GIP databank, The Netherlands [online]. Available from http://www.gipdatabank.nl/index.asp [Accessed 23 June 2006].

6. Ballenger, J.C., Davidson, J.R., Lecrubier, Y., Nutt, D.J., Goldberg, D., Magruder, K.M., Schulberg, H.C., Tylee, A., Wittchen, H.U., 1999. Consensus statement on the primary care management of depression from the International Consensus Group on Depression and Anxiety. J. Clin. Psychiatry 60 (Suppl 7), 54-61.

7. Barbui, C., Campomori, A., D'Avanzo, B., Negri, E., Garattini, S., 1999. Antidepressant drug use in Italy since the introduction of SSRIs: national trends, regional differences and impact on suicide rates. Soc. Psychiatry Psychiatr. Epidemiol. 34, 152-156.

8. Barbui, C., Broglio, E., Laia, A.C., D'Agostino, S., Enrico, F., Ferraro, L., Fiorio, E., Miletti, F., Pietraru, C., Poggio, L., Tognoni, G., 2003. Cross-sectional database analysis of antidepressant prescribing in Italy. J. Clin. Psychopharmacol. 23, 31-34.

9. Bingefors, K., Isacson, D., Von Knorring, L., Smedby, B., Ekselius, L., Kupper, L.L., 1996. Antidepressant-treated patients in ambulatory care long-term use of non-psychotropic and psychotropic drugs. Br. J. Psychiatry 168, 292-298.

10. Claxton, A.J., Li, Z., McKendrick, J., 2000. Selective serotonin reuptake inhibitor treatment in the UK: risk of relapse or recurrence of depression. Br. J. Psychiatry 177, 163-168.

11. Colombo, B., Annovazzi, P.O., Comi, G., 2004. Therapy of primary headaches: the role of antidepressants. Neurol. Sci. 25 (Suppl 3), S171-S175.

12. de Waal, M.W., Stolk, J., van Marwijk, H.W., Springer, M.P., 1996. Voorschrijven van antidepressiva in de huisartspraktijk (Prescription of antidepressants in family practice). Ned. Tijdschr. Geneeskd. 140, 2131-2134.

13. Egberts, A.C.G., Stuijt, C.C.M., Heerdink, E.R., Leufkens, H.G.M., 1998. Indicaties voor het begruik van antidepressiva (Indications for antidepressant drug use). Pharm. Weekbl. 133, 776-780.

14. Hansen, D.G., Sondergaard, J., Vach, W., Gram, L.F., Rosholm, J.U., Kragstrup, J., 2003. Antidepressant drug use in general practice: inter-practice variation and association with practice characteristics. Eur. J. Clin. Pharmacol. 59, 143-149.

15. Helgason, T., Tomasson, H., Zoega, T., 2004. Antidepressants and public health in Iceland. Time series analysis of national data. Br. J. Psychiatry 184, 157-162.

16. Hemels, M.E., Koren, G., Einarson, T.R., 2002. Increased use of antidepressants in Canada: 1981-2000. Ann. Pharmacother. 36, 1375-1379.

17. Henriksson, S., Boethius, G., Hakansson, J., Isacsson, G., 2003. Indications for and outcome of antidepressant medication in a general population: a prescription database and medical record study, in Jamtland County, Sweden, 1995. Acta Psychiatr. Scand. 108, 427-431.

18. Joffe, R.T., Iskedjian, M., Einarson, T.R., O'Brien, B.J., Stang, M.R., 2001. Examining the Saskatchewan health drug database for antidepressant use: the case of fluoxetine. Can. J. Clin. Pharmacol. 8, 146-152.

19. Lamberts, H., Wood, M., 1987. International Classification of Primary Care. Oxford University Press, Oxford.

20. Lawrenson, R.A., Tyrer, F., Newson, R.B., Farmer, R.D., 2000. The treatment of depression in UK general practice: selective serotonin reuptake inhibitors and tricyclic antidepressants compared. J. Affect. Disord. 59, 149-157.

21. Maizels, M., McCarberg, B., 2005. Antidepressants and antiepileptic drugs for chronic noncancer pain. Am. Fam. Phys. 71, 483-490.

22. Meijer, W.E., Heerdink, E.R., Leufkens, H.G., Herings, R.M., Egberts, A.C., Nolen, W.A., 2004. Incidence and determinants of long-term use of antidepressants. Eur. J. Clin. Pharmacol. 60, 57-61.

23. Melfi, C.A., Croghan, T.W., 1999. Use of claims data for research on treatment and outcomes of depression care. Med. Care 37, AS77-AS80. 
24. Pirraglia, P.A., Stafford, R.S., Singer, D.E., 2003. Trends in prescribing of selective serotonin reuptake inhibitors and other newer antidepressant agents in adult primary care. Prim. Care Companion J. Clin. Psychiat. 5, 153-157.

25. Pladevall, M., Williams, L.K., Potts, L.A., Divine, G., Xi, H., Lafata, J.E., 2004. Clinical outcomes and adherence to medications measured by claims data in patients with diabetes. Diabetes Care 27, 2800-2805.

26. Rahimtoola, H., Buurma, H., Tijssen, C.C., Leufkens, H.G., Egberts, A.C., 2003. Incidence and determinants of antidepressant drug use in migraine patients. Int. Clin. Psychopharmacol. 18, 331-339.

27. Roberts, R.E., Shema, S.J., Kaplan, G.A., Strawbridge, W.J., 2000. Sleep complaints and depression in an aging cohort: a prospective perspective. Am. J. Psychiatry 157, 81-88.

28. Rosholm, J.U., Gram, L.F., Isacsson, G., Hallas, J., Bergman, U., 1997. Changes in the pattern of antidepressant use upon the introduction of the new antidepressants: a prescription database study. Eur. J. Clin. Pharmacol. 52, 205-209.

29. Stafford, R.S., MacDonald, E.A., Finkelstein, S.N., 2001. National patterns of medication treatment for depression, 1987 to 2001. Prim. Care Companion J. Clin. Psychiat. 3, 232-235.

30. Tamblyn, R., Lavoie, G., Petrella, L., Monette, J., 1995. The use of prescription claims databases in pharmacoepidemiological research: the accuracy and comprehensiveness of the prescription claims database in Quebec. J. Clin. Epidemiol. 48, 999-1009.

31. Volkers, A., de Jong, A., de Bakker, D., van Dijk, L., 2005. Doelmatig voorschrijven van antidepressiva in de huisartspraktijk (Effective prescribing of antidepressants in general practice). NIVEL, Utrecht.

32. Walsh, J.K., 2004. Pharmacologic management of insomnia. J. Clin. Psychiatry 65 (Suppl 16), 41-45.

33. Westert, G.P., Schellevis, F.G., de Bakker, D.H., Groenewegen, P.P., Bensing, J.M., van der Zee, J., 2005. Monitoring health inequalities through general practice: the Second Dutch National Survey of General Practice. Eur. J. Public Health 15, 59-65.

34. Zinner, N.R., Koke, S.C., Viktrup, L., 2004. Pharmacotherapy for stress urinary incontinence: present and future options. Drugs 64, 1503-1516. 